Article

\title{
Cancer Cells Promote Phenotypic Alterations in Hepatocytes at the Edge of Cancer Cell Nests to Facilitate Vessel Co-Option Establishment in Colorectal Cancer Liver Metastases
}

\author{
Miran Rada *(D), Migmar Tsamchoe ${ }^{\dagger} \mathbb{D}$, Audrey Kapelanski-Lamoureux ${ }^{\dagger}$, Nour Hassan, Jessica Bloom, \\ Stephanie Petrillo, Diane H. Kim, Anthoula Lazaris (D) and Peter Metrakos*
}

Citation: Rada, M.; Tsamchoe, M.; Kapelanski-Lamoureux, A.; Hassan, N.; Bloom, J.; Petrillo, S.; Kim, D.H.; Lazaris, A.; Metrakos, P. Cancer Cells Promote Phenotypic Alterations in Hepatocytes at the Edge of Cancer Cell Nests to Facilitate Vessel Co-Option Establishment in Colorectal Cancer Liver Metastases. Cancers 2022, 14, 1318. https:// doi.org/10.3390/cancers14051318

Academic Editor: David A. Geller

Received: 13 December 2021

Accepted: 1 March 2022

Published: 4 March 2022

Publisher's Note: MDPI stays neutral with regard to jurisdictional claims in published maps and institutional affiliations.

Copyright: (C) 2022 by the authors. Licensee MDPI, Basel, Switzerland. This article is an open access article distributed under the terms and conditions of the Creative Commons Attribution (CC BY) license (https:// creativecommons.org/licenses/by/ $4.0 /)$.
Cancer Research Program, Research Institute of the McGill University Health Centre, Montreal, QC H4A 3J1, Canada; migmar.tsamchoe@mail.mcgill.ca (M.T.); audrey.kapelanski-lamoureux@mail.mcgill.ca (A.K.-L.); nour.hassan@mail.mcgill.ca (N.H.); jessica.bloom@mail.mcgill.ca (J.B.); stephanie.petrillo@muhc.mcgill.ca (S.P.); hyunbin.kim@mail.mcgill.ca (D.H.K.); anthoula.lazaris@mail.mcgill.ca (A.L.)

* Correspondence: miran.rada@mail.mcgill.ca (M.R.); peter.metrakos@mcgill.ca (P.M.);

Tel.: +1-514-934-1934 (ext. 35773) (M.R.); +1-514-843-1600 (ext. 31600) (P.M.)

+ These authors contributed equally to this work.

Simple Summary: Tumour cells in colorectal cancer liver metastases (CRCLM) obtain their blood supply via two major mechanisms: (i) sprouting angiogenesis, through the generation of new vessels; (ii) vessel co-option, where the cancer cells hijack the pre-existing vasculature. The current treatment for CRCLM targets angiogenesis; however, these treatments are ineffective on cancer cells utilizing vessel co-option to gain their blood supply. Our study suggests that cancer cells stimulate phenotypic alterations in the cells of surrounding liver tissue (hepatocytes) in vessel co-opting lesions. These modifications facilitate cancer cells to infiltrate through the liver tissue and hijack the pre-existing vasculature to obtain oxygen and nutrients.

Abstract: Vessel co-option is correlated with resistance against anti-angiogenic therapy in colorectal cancer liver metastases (CRCLM). Vessel co-opting lesions are characterized by highly motile cancer cells that move toward and along the pre-existing vessels in the surrounding nonmalignant tissue and co-opt them to gain access to nutrients. To access the sinusoidal vessels, the cancer cells in vessel co-opting lesions must displace the hepatocytes and occupy their space. However, the mechanisms underlying this displacement are unknown. Herein, we examined the involvement of apoptosis, autophagy, motility, and epithelial-mesenchymal transition (EMT) pathways in hepatocyte displacement by cancer cells. We demonstrate that cancer cells induce the expression of the proteins that are associated with the upregulation of apoptosis, motility, and EMT in adjacent hepatocytes in vitro and in vivo. Accordingly, we observe the upregulation of cleaved caspase-3, cleaved poly (ADP-ribose) polymerase-1 (PARP-1) and actin-related protein 2/3 (ARP2/3) in adjacent hepatocytes to cancer cell nests, while we notice a downregulation of E-cadherin. Importantly, the knockdown of runt-related transcription factor 1 (RUNX1) in cancer cells attenuates the function of cancer cells in hepatocytes alterations in vitro and in vivo. Altogether, our data suggest that cancer cells exploit various mechanisms to displace hepatocytes and access the sinusoidal vessels to establish vessel co-option.

Keywords: vessel co-option; hepatocytes; apoptosis; autophagy; EMT; motility

\section{Introduction}

Colorectal cancer (CRC) is the third most common diagnosed cancer and the second leading cause of cancer death worldwide [1]. Metastases account for most of the CRCrelated death [2,3]. At the time of diagnosis, approximately $25 \%$ of patients with CRC are 
diagnosed with synchronous metastases [4]. Additionally, 30-40\% of the patients are found to develop metachronous metastases and another $25-30 \%$ of the patients develop liver metastases during the follow-up [4]. Currently, surgical resection is the main treatment approach for CRCLM patients, which can achieve 5-year survival rates above 50\%. However, only $20 \%$ of the patients are qualified for upfront surgery and the rest are left with palliative options $[5,6]$.

Two major histopathological heterogeneity have been described in CRCLM, including the desmoplastic histopathological growth pattern (DHGP) and replacement histopathological growth pattern (RHGP) [7-10]. In DHGP lesions, the cancer cells are prevented from direct contact with hepatocytes by a desmoplastic rim and obtain their blood supply through angiogenesis [8,10]. In contrast, the cancer cells in RHGP lesions are in direct contact with hepatocytes due to the lack of a desmoplastic ring and obtain their blood supply through the co-option of the existing vasculature, i.e., the tumour incorporates pre-existing blood vessels instead of promoting angiogenesis [8,10-12].

The liver vascular architecture is characterized by sinusoidal vessels. In order to access the sinusoidal vessels, the cancer cells must invade the liver parenchyma [8,11], as well as displace the hepatocytes around sinusoidal vessels and occupy their space [13]. We previously hypothesized that the cancer cells could form a unique microenvironment to induce hepatocyte displacement through different pathways, such as apoptosis, necrosis, and/or autophagy, as well as an elevated motility and epithelial-mesenchymal transition (EMT) [13]. However, the molecular mechanisms involved in hepatocytes displacement are not yet clearly defined.

Apoptosis is a type of programmed cell death characterized by various energydependent biochemical events resulting in changes in cellular morphology and death [14]. The caspase (e.g., caspase-3)-mediated cleavage of poly (ADP-ribose) polymerase-1 (PARP1 ) cleavage is recognized as a hallmark of apoptosis $[15,16]$. Apoptosis plays an essential role in tumour development and cancer metastases [17-20]. The evasion of cancer cells from apoptosis is associated with resistance to therapeutic agents [18,21]. It is still unclear whether apoptosis is involved in the development of vessel co-option, specifically in CRCLM. However, a differential expression of apoptotic genes has been reported between angiogenic and nonangiogenic lesions in non-small-cell lung cancer (NSCLC) [22,23]. Accordingly, the angiogenic lesions expressed higher levels of antiapoptotic genes, including ANXA7 and SOD1, while the proapoptotic genes, including FOS, FAH, and PRODH, were upregulated in nonangiogenic lesions [22].

Another candidate mechanism of hepatocyte displacement by cancer cells in vessel co-opting CRCLM is autophagy [13]. Autophagy, a "self-eating" phenomenon, is an intracellular degradative pathway to maintain cell function and survival [24]. Autophagy plays a critical role in liver protection against injury and steatosis [25]. Autophagy is known to induce tumour development and drug resistance in the liver [24]. Despite the ample evidence for a positive correlation between autophagy with antiangiogenic (e.g., bevacizumab) therapy resistance in various cancers [26,27], the role of autophagy in the establishment of vessel co-opting tumours is still unclear.

EMT is another potential mechanism that may expedite hepatocyte displacement in vessel co-opting CRCLM [13]. EMT comprises multiple biochemical modifications to allow epithelial cells to develop a mesenchymal cell phenotype, such as an elevated migration capacity and the production of extracellular matrix (ECM) components [28]. It has been reported that EMT in cancer cells contributes to tumour progression, metastases, and resistance to cancer treatment [29]. Indeed, EMT plays an important role in promoting cancer cell motility $[30,31]$. We recently demonstrated the upregulation of EMT and motility biomarkers in the cancer cells of vessel co-opting CRCLM lesions, which correlated with the upregulation of transforming growth factor beta 1 (TGF $\beta 1$ ) in their proximate liver parenchyma [32]. It is worth mentioning that the role of EMT in the cells of the organ that hosts tumours is poorly investigated. In injured livers, hepatocytes have been shown to undergo EMT [33], which is promoted mainly through TGF $\beta 1$ [34]. 
In the current study, we explored the contribution of apoptosis, autophagy, EMT, and motility in hepatocyte displacement by cancer cells in vessel co-opting CRCLM. Our results propose that the cancer cells in the tumour-liver interface of co-opting lesions stimulate the displacement of the hepatocytes through the upregulation of proteins that are associated with high levels of apoptosis, motility, and EMT in hepatocytes and, consequently, occupy their space to co-opt the sinusoidal blood vessels. Thus, our results indicate that the metastatic cancer cells alter the hepatocytes phenotype in vessel co-opting CRCLM lesions to support their co-option of the pre-existing blood vessels.

\section{Methods}

\subsection{Patient Samples}

This study was approved by the McGill University Health Centre Institutional Review Board. All patients signed the informed consent.

\subsection{Cells Culturing and Treatment}

The cells were cultured at $37{ }^{\circ} \mathrm{C}$ with $5 \% \mathrm{CO}_{2}$ in DMEM (Wisent Inc., St-Bruno, QC, Canada, \#319-005-CL) supplemented with 10\% FBS (Wisent Inc., \#085-150) and 1\% of streptomycin penicillin/streptomycin $(10,000$ units $/ \mathrm{mL}$ of penicillin and $10,000 \mu \mathrm{g} / \mathrm{mL})$ (Wisent Inc., 450-201-EL).

Indirect coculturing was performed with 6-well inserts (Falcon, Glendale, AZ, USA, \#353090) and companion plates (Falcon, Glendale, AZ, USA, \#353502) as described previously [32]. The cells were seeded in DMEM supplemented with $10 \%$ FBS and $1 \times$ penicillin/streptomycin overnight. The next day, the growth medium was replaced with serum-free DMEM, and the cells were incubated for $48 \mathrm{~h}$ at $37^{\circ} \mathrm{C}$.

The treatment of IHH cells with recombinant TGF $\beta 1$ was performed as published previously [32]. Briefly, the IHH cells were grown as mentioned above. After $24 \mathrm{~h}$, the conditioned media was replaced with serum-free DMEM media supplemented with recombinant TGF $\beta 1$ (Peprotech, Cranbury, NJ, USA, \# 100-21) and incubated for $24 \mathrm{~h}$ at $37^{\circ} \mathrm{C}$.

\subsection{Lentiviral shRNA Knockdown}

The lentiviral vectors were produced in 293T cells using the calcium phosphate method [32,35]. We used the following constructs: Scrambled shRNA\#: SHC016, RUNX1\#1: TRCN0000338428. A monolayer of HT29 cancer cells was prepared as mentioned above. After $24 \mathrm{~h}$, the lentivirus-containing medium supplemented with $8 \mu \mathrm{g} / \mathrm{mL}$ of polybrene was added to HT29 cancer cells and incubated for $72 \mathrm{~h}$ at $37{ }^{\circ} \mathrm{C}$ with $5 \% \mathrm{CO}_{2}$, followed by treatment with $1 \mu \mathrm{g} / \mathrm{mL}$ of Puromycin (Wisent Inc., St-Bruno, QC, Canada, 450-162-XL).

\subsection{Immunoblotting}

After harvesting the cells, the lysates were prepared by resuspending the cells in RIPA buffer (Sigma Aldrich, Oakville, ON, Canada, \#R0278) supplemented with protease inhibitor (Sigma Aldrich, \#4693124001). To rupture the cells, the resuspended cells passed through a $25 \mathrm{G}$ needle 15 times. The protein content in the samples was measured using BCA Protein Assay Kit (Thermo Scientific, Saint-Laurent, QC, Canada, \#23225). The generated lysates were used for immunoblotting with following antibodies: GAPDH 1:2000 (Abcam, Waltham, MA, USA, \#ab9485), cleaved caspase-3 1:500 (Cell signaling, \# 9664S), cleaved PARP-1 1:500 (Cell signaling, \# 5625S), ARP2/3 1:1000 (Millipore, \#MABT95), Vimentin 1:1000 (Abcam, Waltham, MA, USA, \#ab16700), RUNX1 1:500 (LS Bio, Seattle WA, USA, \#LS-C353932), TGFß1 1:500 (Abcam, Waltham, MA, USA, \#ab215715).

\subsection{Immunohistochemical Staining}

Ten independent formalin-fixed paraffin-embedded (FFPE) CRCLM sections ( $n=5$ RHGP; $n=5$ DHGP) were procured and used for each staining as a biological replicate. In brief, the sections were deparaffinized with xylene (Leica, Heerbrugg, Switzerland, 
\#3803665) followed by hydration with ethanol (Greenfield, Boucherville, QC, Canada, \#P016EAAN) and then with distilled water. Then, the sections were exposed to antigen retrieval, as well as endogenous peroxidase inhibition (Dako, \#S2003). The sections were incubated with $1 \%$ goat serum buffer for $1 \mathrm{~h}$ followed by primary antibody in $1 \%$ goat serum overnight at $4{ }^{\circ} \mathrm{C}$. The next day, the sections were washed and incubated with secondary antibodies (Dako, Burlington, ON, Canada, anti-mouse: \#K4001; anti-rabbit: \#K4003) for $1 \mathrm{~h}$. The positive signals were stained with diaminobenzidine (DAB) substrate (Dako, Burlington, ON, Canada, \#K3468). The sections were scanned at $20 \times$ magnification (Aperio ScanScope XT System) and the images were analyzed with Aperio ImageScope ver.11.2.0.780 as published previously [10-12].

The following primary antibodies were used: cleaved caspase-3 1:100 (Cell signaling, Whitby, ON, Canada, \# 9664S), cleaved PARP-1 1:50 (Cell signaling, Whitby, ON, Canada, \# 5625S), E-Cadherin 1:200 (Cell signaling, Whitby, ON, Canada, \# 3195S; R\&D systems, Toronto, ON, Canada, \#MAB1838-100), ARP2/3 1:300 (Millipore, Etobicoke, ON, Canada, \#MABT95; Bioss, Laval, QC, Canada, \#bs-12524R), RUNX1 1:200 (LS Bio, Seattle WA, USA, \#LS-C353932).

\subsection{Immunofluorescence Staining}

We performed immunofluorescent (IF) staining for specimens as described previously [32]. In brief, the sections were deparaffinized with xylene (Leica, \#3803665), hydrated with ethanol (Comalc, \#P016EAAN), as well as distilled water. Antigen retrieval was performed followed by blocking with $1 \%$ goat serum buffer ( $1 \mathrm{~h}$ incubation at room temperature) and primary antibody (overnight incubation at $4^{\circ} \mathrm{C}$ ). The sections were washed thrice and incubated with secondary antibody 1:1000 (Alexa Flour 594 goat anti-rabbit IgG and Alexa Flour 488 goat anti-mouse IgG (Invitrogen, Burlington, ON, Canada, \#A11037 and \#A10680, respectively)) for $2 \mathrm{~h}$ at room temperature, followed by washing. The sections were incubated with DAPI 1:1000 (Thermo Fisher Scientific, Saint-Laurent, QC, Canada, D1306) for $10 \mathrm{~min}$ and covered with cover glass using ProLong Gold Antifade Mountant (Thermo Fisher Scientific, Saint-Laurent, QC, Canada, P36934). Six independent tumour specimens, including RHGP $(n=3)$ and DHGP $(n=3)$, were procured and used for each staining as a biological replicate.

We performed IF staining for cultured cells, which followed the protocol [32]. In brief, the cells were fixed with 4\% paraformaldehyde (Biolegend, San Diego, CA, USA, \#420801), permeabilized with 0.1\% Triton X-100 (Bio-Rad, Saint-Laurent, QC, Canada, \#161-0407), blocked with 5\% BSA (GE Healthcare Life Science, Chicago, IL, USA, \#SH30574.02), and incubated with primary antibody prepared with $5 \%$ BSA at $4{ }^{\circ} \mathrm{C}$ overnight. The next day, the cells were washed and incubated with secondary antibodies 1:1000 (Alexa Flour 594 goat anti-rabbit IgG and Alexa Flour 488 goat anti-mouse IgG (Invitrogen, Burlington, ON, Canada, \#A11037 and \#A10680, respectively)) for $2 \mathrm{~h}$. The cells were then incubated with DAPI 1:1000 for $10 \mathrm{~min}$ and covered with coverslips using ProLong Gold Antifade Mountant (Thermo Fisher Scientific, Saint-Laurent, QC, Canada, \#P36934).

The sections were examined with Zeiss LSM780 confocal microscope. The intensity of positive signals was analyzed using ImageJ (NIH, Bethesda, MD) software. Average pixel intensity was measured from three randomly selected areas for each sample. We used these antibodies: HSA 1:300 (Santa Cruz, Dallas, TX, USA, \#SC5893), cleaved caspase-3 1:100 (Cell signaling, \# 9664S), cleaved PARP-1 1:50 (Cell signaling, \# 5625S), ARP2/3 1:300 (Millipore, \#MABT95), Vimentin 1:200 (Abcam, ab16700), CK20 (Thermo Fisher, Saint-Laurent, QC, Canada, \#MA5-13263), E-Cadherin 1:200 (Cell signaling, \# 3195S).

\subsection{Scratch Assay}

The cells were seeded in a treated plate with poly-L-Lysine (Millipore, \#A-005-CL) and incubated with DMEM supplemented with $10 \%$ FBS and 1\% penicillin/streptomycin at $37{ }^{\circ} \mathrm{C}$ overnight. The next day, the medium was removed and a wound was introduced into the monolayer cells using a p200 pipette tip (Kinesis, Montreal, QC, Canada, \#TF-200- 
R-S) [11,32]. The cells were washed with PBS and the stripped areas were photographed $(0 \mathrm{~h})$ and incubated for $24 \mathrm{~h}$ at $37^{\circ} \mathrm{C}$ with serum-free DMEM. The cells were washed with PBS and the stripped areas were snapped $(24 \mathrm{~h})$. The wound opening was analyzed with ImageJ (NIH, Bethesda, MD).

\subsection{MTT Assay}

IHH hepatocytes and cancer (LS174, SW620 or HT29) cells were seeded at a density of 500,000 cells/well in 6-well companion plates and inserts, respectively. The cells were cultured in DMEM supplemented with $10 \%$ FBS and $1 \%$ penicillin/streptomycin at $37^{\circ} \mathrm{C}$ with $5 \% \mathrm{CO}_{2}$. The next day, the conditioned media were replaced with serum-free DMEM media and the cells were incubated at $37^{\circ} \mathrm{C}$. After $48 \mathrm{~h}$, the media was aspirated and MTT assay (Abcam, \#Ab211091) was performed according to the manufacturer's protocol. Briefly, cells were incubated with $500 \mu \mathrm{L}$ serum-free DMEM media and $500 \mu \mathrm{L}$ MTT reagent and incubated the plate at $37^{\circ} \mathrm{C}$ for $3 \mathrm{~h}$. After incubation, we added $1500 \mu \mathrm{L}$ of MTT solvent into each well and incubated for $15 \mathrm{~min}$. Absorbance was, subsequently, measured at $590 \mathrm{~nm}$ using the Tecan Ultra plate reader (Tecan, Germany).

\subsection{Statistical Analysis}

Data were analyzed with GraphPad Prism software version 7.0 (GraphPad Software, CA, USA). Data presented as mean \pm standard deviation. Unpaired Student's $t$-test was used to determine a significant difference between the means of the two groups. A $p$-value of less than 0.05 was considered significant.

\section{Results}

\subsection{Upregulation Pression of Proapoptotic Biomarker Vessel Co-Opting Lesions}

Hepatocyte replacement by cancer cells was frequently observed at the edge of cancer cell nests in vessel co-opting RHGP lesions, which allowed the cancer cells to take over the hepatocyte-occupied space to hijack the sinusoids and obtain a blood supply $[8,10,13]$. However, the mechanistic pathways underlying hepatocyte replacement by cancer cells are poorly understood. We postulated that apoptosis may contribute to hepatocyte replacement by cancer cells. To test this possibility, we performed immunohistochemical staining for chemonaive CRCLM specimens ( $n=5$ DHGP; $n=5$ RHGP) using proapoptotic biomarkers, including cleaved caspase- 3 or cleaved PARP-1 antibody [18,21,36,37]. Indeed, our results suggested a significant increase in the expression levels of cleaved caspase- 3 and cleaved PARP-1 in hepatocytes that were neighbouring cancer cells in vessel co-opting RHGP lesions (Figure 1a,b). Conversely, we observed a lower expression of both proteins in adjacent hepatocytes of angiogenic DHGP lesions. To further validate our results and confirm that the hepatocytes were the main source of both cleaved caspase- 3 and cleaved PARP-1 in vessel co-opting lesions, we performed co-immunofluorescent (co-IF) staining for chemonaive CRCLM samples ( $n=3$ DHGP; $n=3$ RHGP) with hepatocyte-specific antigen (HSA) and cleaved caspase- 3 or cleaved PARP-1 antibodies. As shown in Figure 1c,d, both cleaved caspase- 3 and cleaved PARP-1 were primarily localized in the hepatocytes. Altogether, our data proposed the upregulation of proapoptotic biomarkers in the hepatocytes of vessel co-opting lesions, specifically, the hepatocytes in close proximity to cancer cells. 


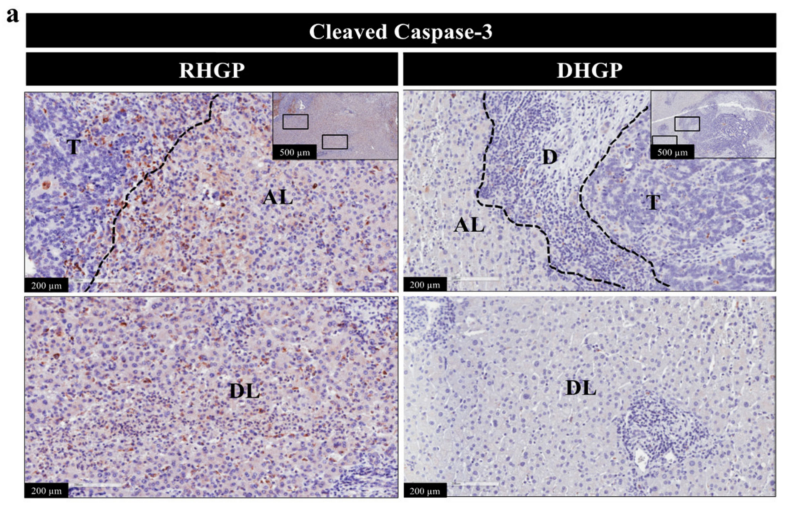

Cleaved Caspase-3 expression
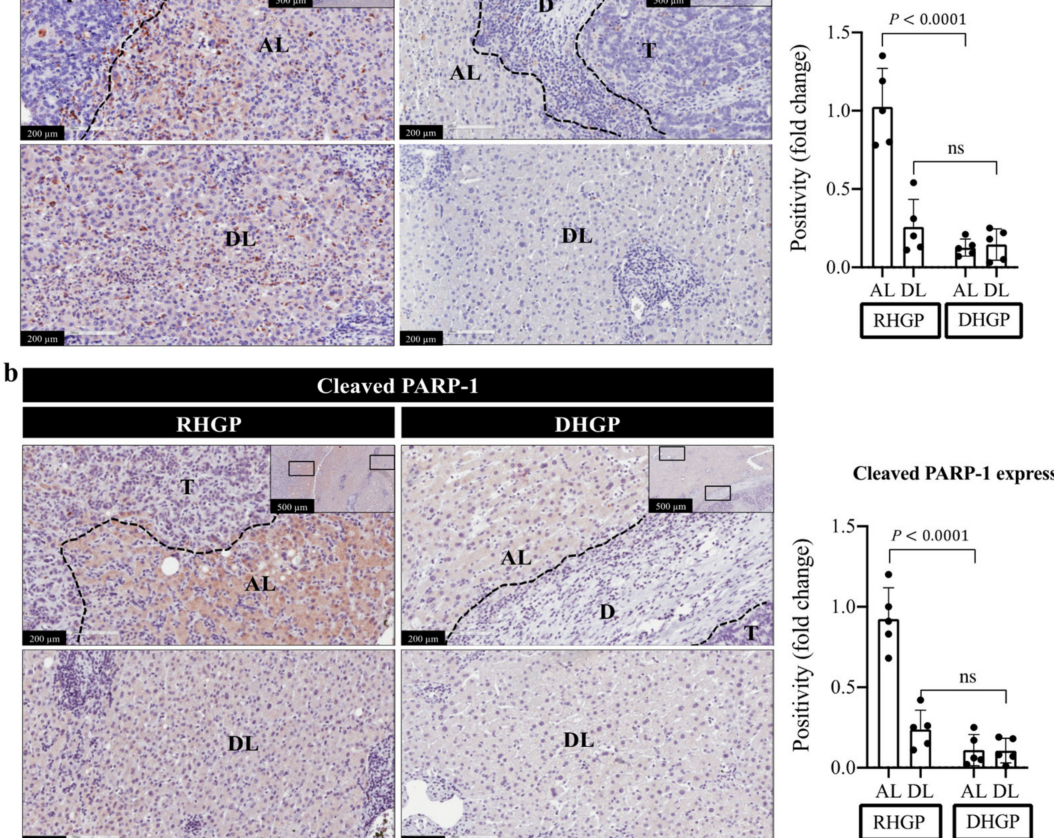

Cleaved PARP-1 expression
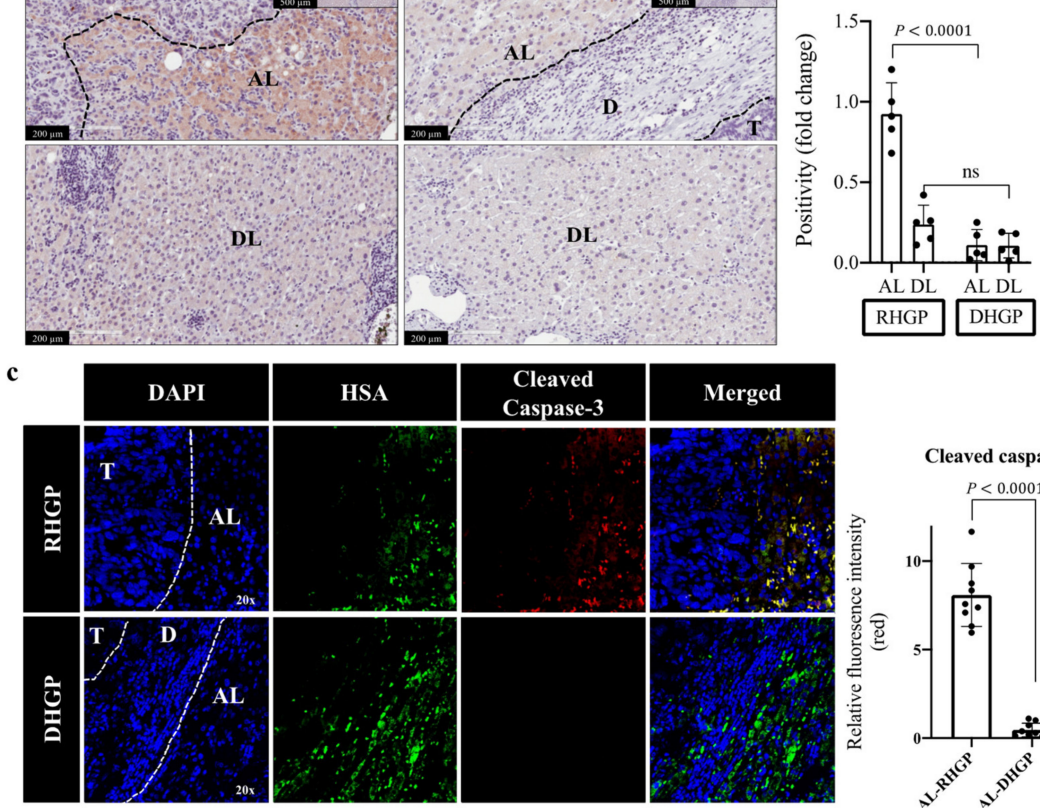

Merged

d
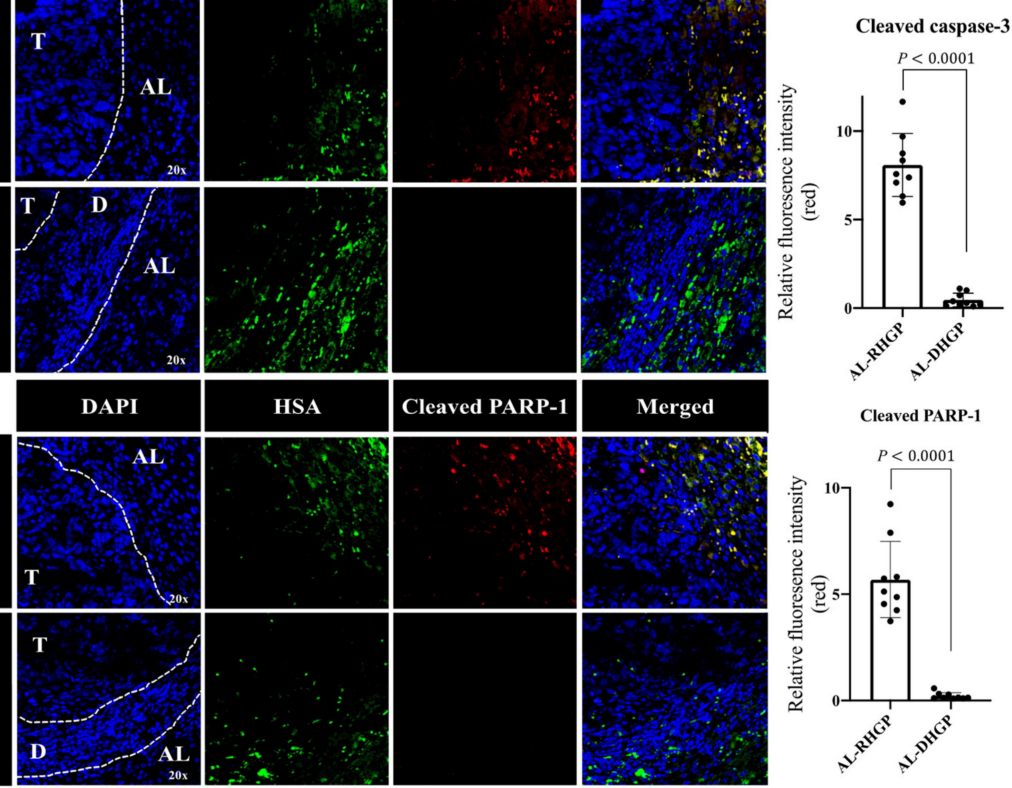

Figure 1. Overexpression of proapoptotic biomarkers in vessel co-opting CRCLM. (a,b) Immunohistochemical staining of chemonaive CRCLM lesions using cleaved caspase-3 and cleaved PARP-1 antibodies, respectively (left panel). The right panels represent quantification of staining positivity that assessed in RHGP $(n=5)$ and DHGP $(n=5)$ lesions using Aperio software. (c,d) co-IF of chemonaive CRCLM lesions showing HSA (green) and cleaved caspase-3 (red) or cleaved PARP-1 (red). The right panels represent the quantification of positive pixels in CRCLM specimens, including RHGP $(n=3)$ and DHGP $(n=3)$. Average pixel intensity was measured from three randomly selected areas for each sample. Data are presented as the mean \pm SD. ns = Not significant. AL-adjacent liver; D-desmoplastic ring; DL-distal liver; T-tumour. 


\subsection{Cancer Cells Stimulate Apoptosis in Hepatocytes In Vitro}

To examine whether cancer cells are responsible for the high expression of proapoptotic markers in hepatocytes, we assessed the expression of proapoptotic markers (cleaved caspase-3 and cleaved PARP-1) in immortalized human hepatocytes (IHH) upon their indirect contact with colorectal cancer (LS174, SW620 or HT29) cells using the insert coculturing approach (Figure 2a). IHH cells are immortalized human hepatocytes that retain various differentiation phenotypes of primary hepatocytes [38-40]. Remarkably, we demonstrated a significant increase in the expression levels of both proapoptotic markers in cocultured IHH hepatocytes with cancer cells (Figures $2 b$ and S5). We also found similar results when we performed immunofluorescence using HSA and cleaved caspase-3 (Figure 2c) or cleaved PARP-1 (Figure 2d) antibodies. Next, we used a direct coculturing system between IHH hepatocytes and HT29 cancer cells to further validate our results (Figure 2e). In this experiment, we used cytokeratin 20 (CK20) [11,32] as a biomarker of colorectal cancer cells, as well as antibodies against cleaved caspase- 3 or cleaved PARP-1. The expression levels of both cleaved caspase-3 (Figure 2f) and cleaved PARP-1 (Figure 2g) were significantly increased in the cocultured hepatocytes compared to control, specifically, in the hepatocytes that were in direct contact with cancer cells. Importantly, we also found a significant reduction in the IHH hepatocyte viability upon coculturing with colorectal cancer (LS174, SW620 or HT29) cells (Supplementary Figure S1). In sum, these data imply that the interactions between cancer cells and hepatocytes upregulate the expression of proapoptotic markers in hepatocytes.

It has been reported that tumour cells stimulate autophagy in neighbouring cells of the tumour microenvironment to support their progression [41,42]. Thus, we questioned whether cancer cells in vessel co-opting CRCLM lesions stimulate autophagy in the adjacent hepatocytes to occupy their space. To address this question, we assessed functional autophagy in chemonaive CRCLM specimens ( $n=5$ DHGP; $n=5$ RHGP) by immunohistochemistry using LC3B and p62/sequestosome 1 (SQSTM1). LC3B and p62 are commonly used as autophagy biomarkers for evaluating autophagy activity [43-45]. LC3B is associated with autophagosome formation, while p62 serves as a selective autophagy substrate, which interacts with the autophagy machinery as an adaptor for the target cargo $[45,46]$. Therefore, the upregulation of LC3B and degradation of p62 can be used as a marker of autophagy [43-45]. We demonstrated no significant differences in the expression of LC3B between hepatocytes of vessel co-opting and angiogenic lesions (Supplementary Figure S2a). However, we noticed a moderate positive staining of LC3B in some hepatocytes that were predominantly located at the adjacent parenchyma of vessel co-opting lesions. Our results also exhibited no significant difference in p62 staining between the liver parenchyma of vessel co-opting and angiogenic lesions (Supplementary Figure S2b). These data indicated that the role of autophagy in hepatocytes displacement was not prominent. 


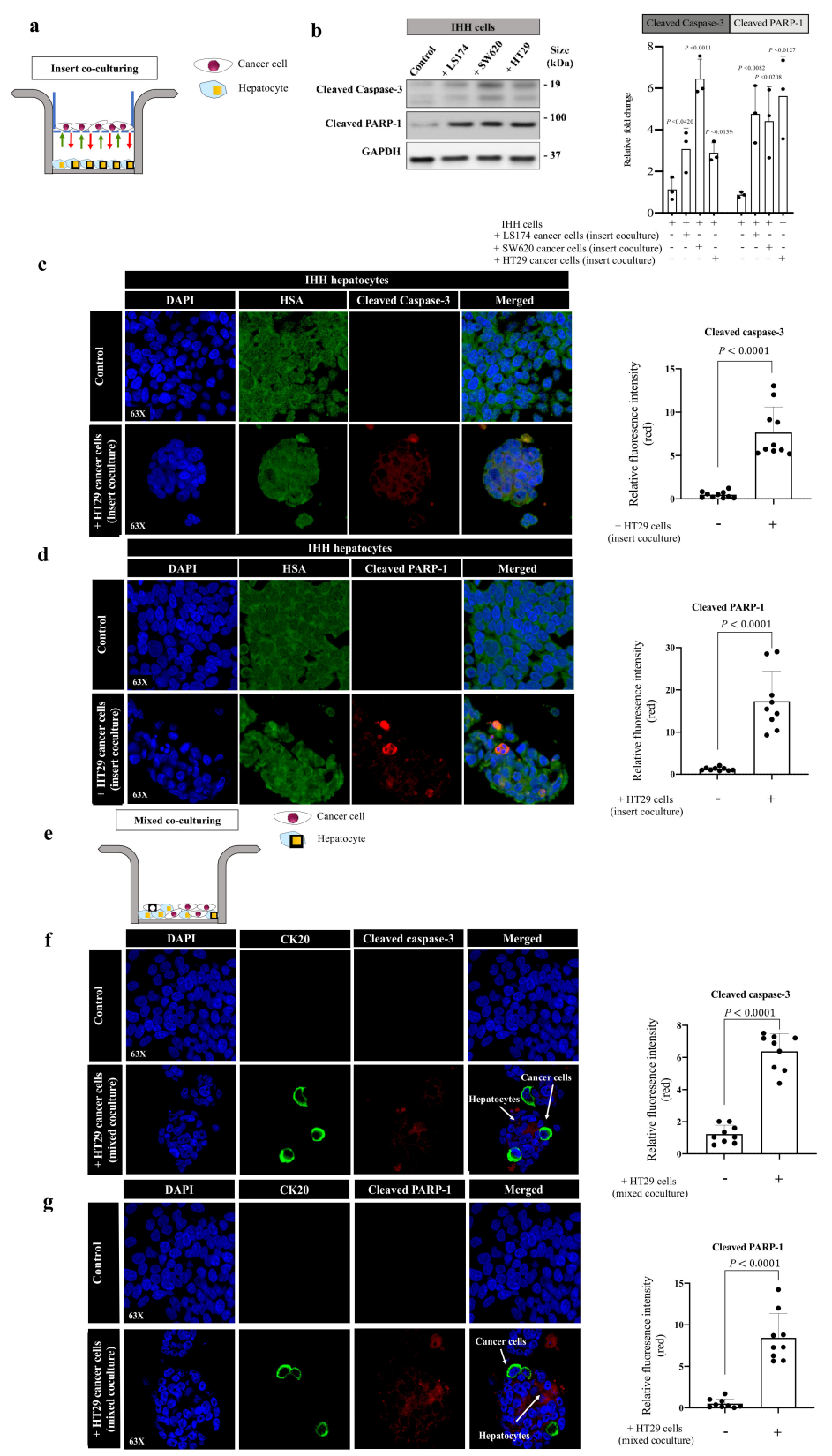

Figure 2. Cancer cells promote apoptosis in hepatocytes in vitro. (a) Schematic illustration of indirect (insert) coculturing system. (b) The left panel shows immunoblotting of cleaved caspase-3 and cleaved PARP-1 in IHH hepatocytes in the presence or absence of indirect contact with colorectal cancer (LS174, SW620 or HT29) cells. The right panel represents the intensity of cleaved caspase-3 and cleaved PARP-1 bands in three independent experiments. (c,d) represent co-immunostaining of IHH hepatocytes indirectly cocultured with HT29 cancer cells using hepatocytes marker, HSA (hepatocytespecific antigen, green), combined with either cleaved caspase- 3 or cleaved PARP-1 (left panel). The right panels represent the quantification of positive pixels. Average pixel intensity was measured from three randomly selected areas for each sample. Results are representative of 3 independent experiments. (e) Schematic showing mixed (direct) coculturing system. $(\mathbf{f}, \mathbf{g})$ Representative images of coimmunostaining for IHH hepatocytes cocultured with HT29 cancer cells using a mixing coculturing system. The cells were stained with cancer cell marker, CK20 (cytokeratin 20, green), combined with either cleaved caspase-3 or cleaved PARP-1 (red). The right panels represent the quantification of positive pixels. Average pixel intensity was measured from three randomly selected areas for each sample. Results are representative of 3 independent experiments. The bar chart shows mean values \pm SD. 


\subsection{Cancer Cells Induce EMT and Motility in Hepatocytes}

Our coculturing data in Figure 2 suggested alterations in the morphology and arrangement of the hepatocytes upon their interaction with cancer cells. Thus, we hypothesized that hepatocytes that are in close contact with cancer cells may acquire a mesenchymal phenotype, which is known to stimulate EMT-derived migration [30,32]. To test our hypothesis, we cocultured IHH hepatocytes with HT29 colorectal cancer cells followed by immunofluorescence co-staining for EMT and motility biomarkers, using vimentin [47] and actin-related protein 2/3 (ARP2/3) [32,48], respectively. Intriguingly, we observed a significant increase in the expression of both markers in hepatocytes that cocultured (insert coculturing) with cancer cells (Figure 3a). Next, we evaluated EMT in CRCLM lesions ( $n=5$ DHGP; $n=5$ RHGP) by immunohistochemical (IHC) staining using the E-cadherin antibody. E-cadherin is a key element of maintaining the epithelial phenotype of cells and its loss is correlated with induced EMT [49]. Our IHC staining demonstrated a significant reduction in E-cadherin protein at the adjacent liver parenchyma of vessel co-opting RHGP lesions in comparison to DHGP lesions (Figure 3b). To corroborate our findings, we performed immunofluorescent co-staining for chemonaive CRCLM specimens ( $n=3$ DHGP; $n=3$ RHGP) using HSA and E-cadherin antibodies. Our data showed that the majority of adjacent hepatocytes to the tumour nests in angiogenic lesions expressed E-cadherin (Figure $3 b$ ). In contrast, we observed significantly lower levels of E-cadherin in the adjacent hepatocytes in vessel co-opting lesions. It is worth mentioning that the cancer cells in angiogenic lesions also expressed higher levels of E-cadherin compared to their vessel co-opting counterparts (Figure 3b). These data indicated that the adjacent hepatocytes in vessel co-opting lesions acquired a mesenchymal phenotype. Importantly, the expression levels of ARP2/3 in the hepatocytes of vessel co-opting RHGP lesions were significantly increased (Figure 4a). Nevertheless, our scratch assay experiment $[11,32]$ confirmed that coculturing (insert coculturing) cancer (SW620 or HT29) cells with IHH hepatocytes significantly induced the motility of hepatocytes (Figure 4b). Taken together, our data proposed that cancer cell interactions with hepatocytes augment EMT and motility in hepatocytes.

\subsection{RUNX1 Is a Key Player in the Interactions between Cancer Cells and Hepatocytes}

Related transcription factor-1 (RUNX1) is a transcriptional factor that controls the transcription of thousands of genes involved in tumour progression [50], as well as angiogenic [51-53] and nonangiogenic tumour vascularization [54,55], including vessel cooption [32]. Recently, we found RUNX1 as a key mediator of vessel co-option development in the CRCLM [32]. Accordingly, the cancer cells of vessel co-opting lesions were characterized by high expression levels of RUNX1, which was associated with an increased motility and EMT [32]. In light of these findings, we hypothesized that the presence of RUNX1 in cancer cells may also play a role in cancer cell-driven hepatocyte phenotype alterations. To test our hypothesis, we generated HT29 cancer cells expressing either control shRNA or shRNA against RUNX1 (Figures 5a and S6). We then performed insert coculturing between the generated HT29 cells and IHH hepatocytes. After 48 h, cell viability was determined in cocultured hepatocytes using an MTT assay. Interestingly, silencing RUNX1 in the cocultured cancer cells abrogated the cytotoxicity of cancer cells against hepatocytes (Figure 5b). Moreover, our IF staining showed that the expression of both cleaved caspase-3 and cleaved PARP-1 in hepatocytes appeared to be dependent on the presence of RUNX1 in the cocultured cancer cells (Figure $5 \mathrm{c}, \mathrm{d}$ ). Similar results were obtained when we cocultured hepatocytes directly with RUNX1-silenced HT29 cancer cells (Supplementary Figure S3a,b). Our IF results also suggested that the presence of RUNX1 in the cancer cells was essential to induce motility and EMT in the adjacent hepatocytes in vitro. As shown in Figure 5e, coculturing RUNX1-silenced HT29 cancer cells with IHH hepatocytes abolished the expression of ARP2/3 and vimentin in the hepatocytes. 

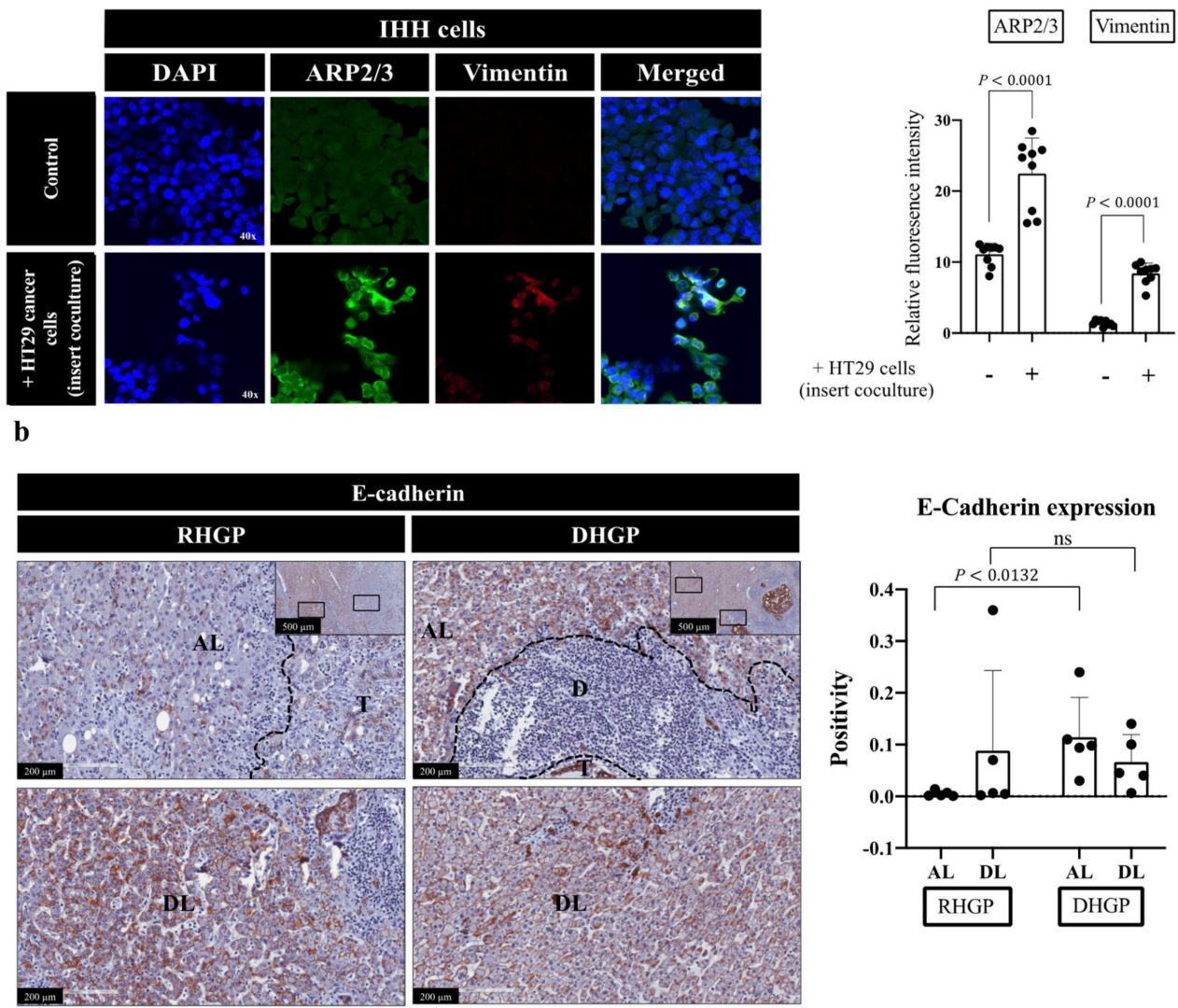

c
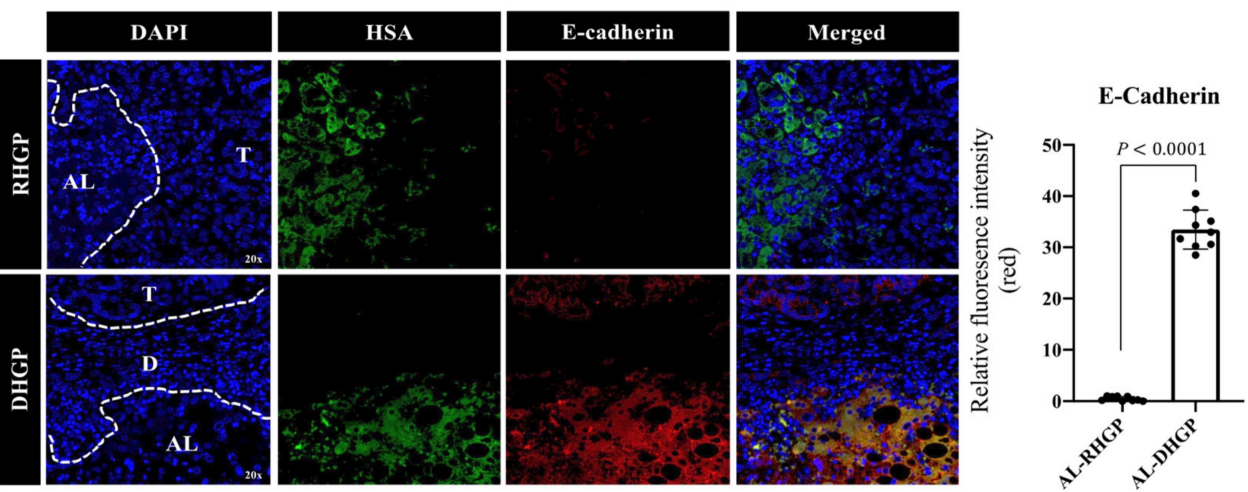

Figure 3. Expression of EMT biomarkers in hepatocytes in vitro and in vivo. (a) Representative images of coimmunostaining and colocalization overlay for $\mathrm{IHH}$ hepatocytes cocultured (insert coculturing) with HT29 cancer cell lines using motility marker, ARP2/3 (green), and EMT marker, vimentin (red). The right panel shows the quantification of positive pixels. Average pixel intensity was measured from three randomly selected areas for each sample. Results are representative of 3 independent experiments. (b) represents immunohistochemical staining for E-Cadherin on FFPE tissue sections of chemonaive CRCLM. The right panels represent quantification of staining positivity that was assessed in RHGP $(n=5)$ and DHGP $(n=5)$ lesions using Aperio software. (c) Representative images of coimmunostaining for showing HSA (green) and E-Cadherin (red) on FFPE tissue sections of CRCLM resected from chemonaive patients. The right panels represent the quantification of positive pixels in CRCLM specimens, including RHGP $(n=3)$ and DHGP $(n=3)$. Average pixel intensity was measured from three randomly selected areas for each sample. AL-adjacent liver; D-desmoplastic ring; DL-distal liver; T-tumour. The bar chart shows mean values \pm SD. ns $=$ Not significant. 
a
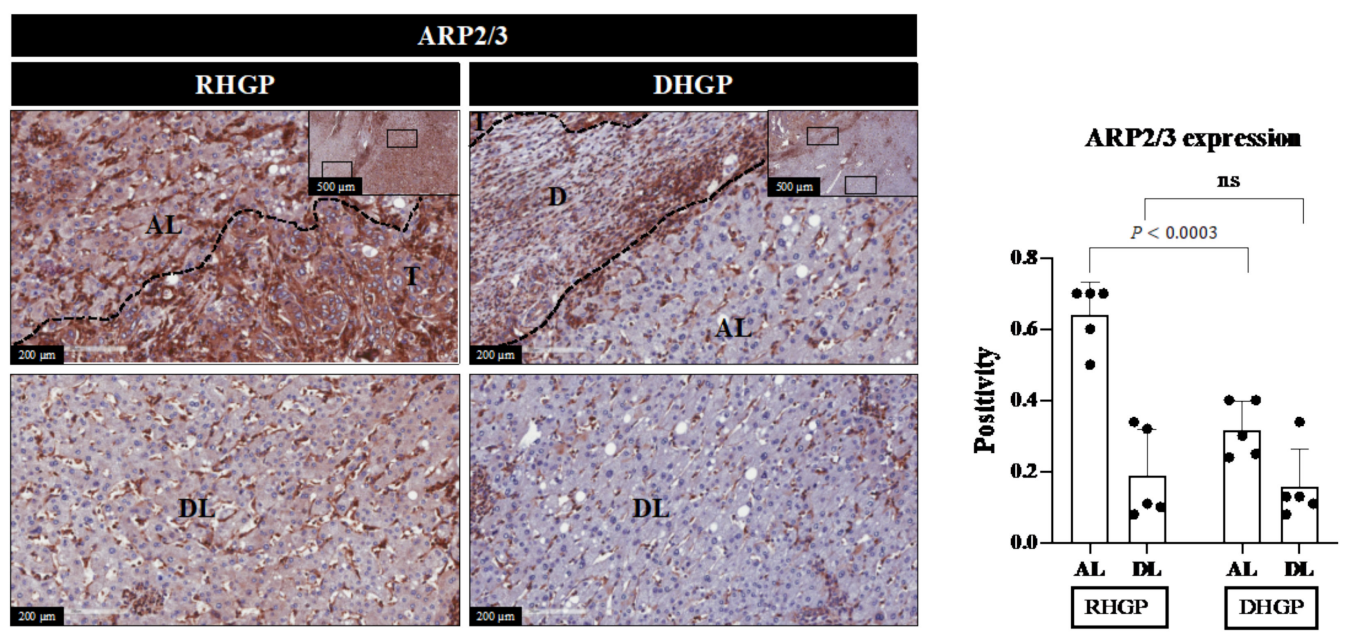

b

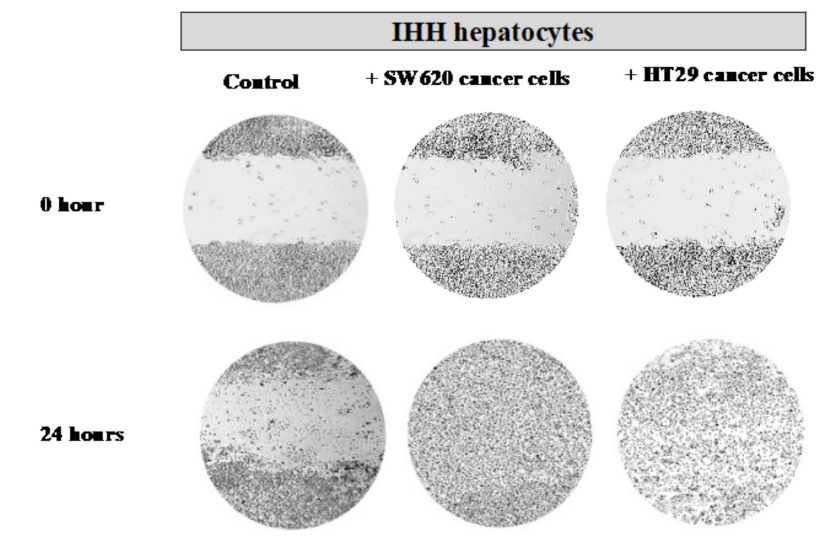

Hours of incubation

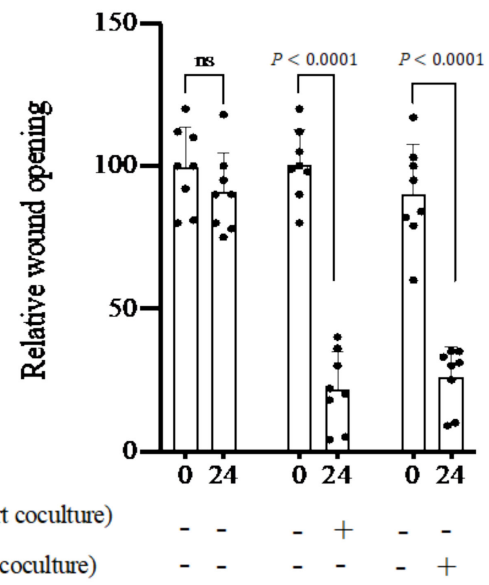

+ HT29 cancer cells (insert coculture)

Figure 4. Hepatocyte motility increased upon their interaction with cancer cells. (a) shows immunohistochemical staining for motility biomarker (ARP2/3) antibody on FFPE tissue sections of chemonaive CRCLM. The right panel represents quantification of staining positivity that was assessed in RHGP $(n=5)$ and DHGP $(n=5)$ lesions using Aperio software. AL-adjacent liver; D-desmoplastic ring; DL-distal liver; T-tumour. (b) Showing scratch assay in IHH hepatocytes upon coculturing (insert coculturing) with colorectal cancer (HT29 or SW620) cells. The experiment was performed in the biological replicate (three wells per experiment). The wound opening was measured and analyzed at 0 and $24 \mathrm{~h}$ using image J software (bottom panel). The bar chart shows mean values \pm SD. $n s=$ Not significant. 


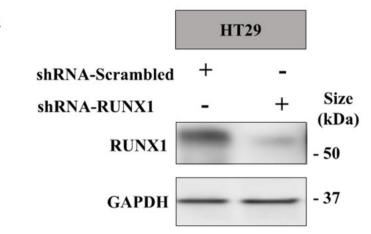

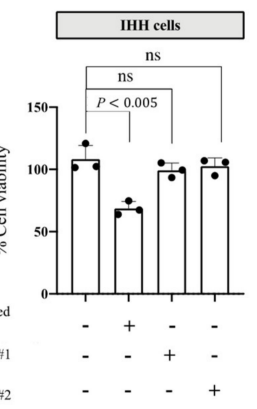

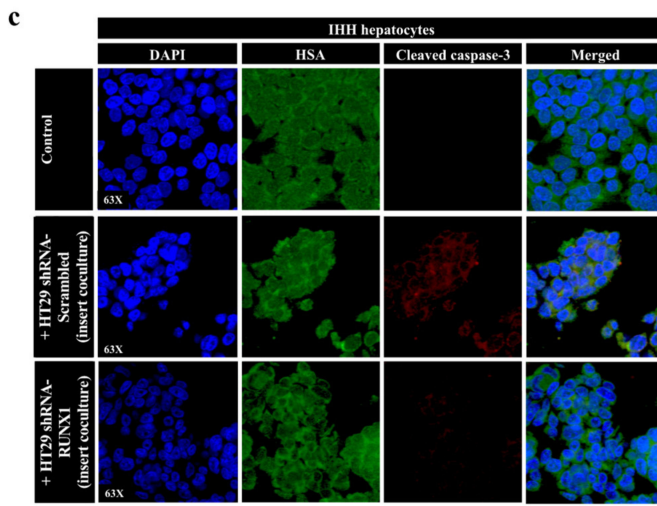

insert coculture)

T29 ShRNA-RUNX1

T29 ShRNA-RUNXI

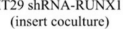

d

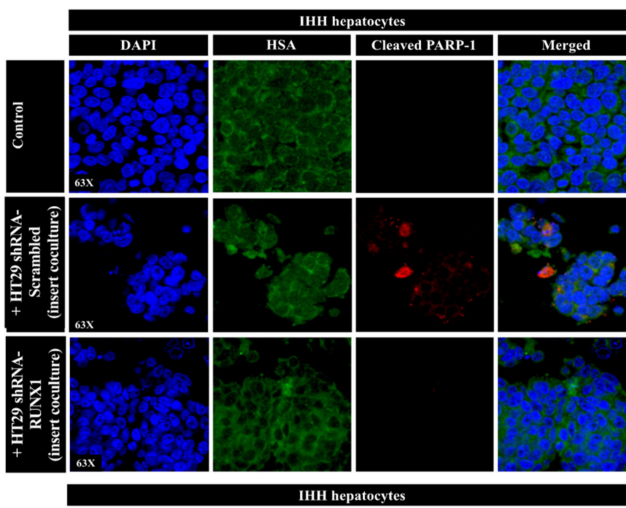

HT29 shRNA-Scrambled cells
HT29 shRNA-RUNXI cells
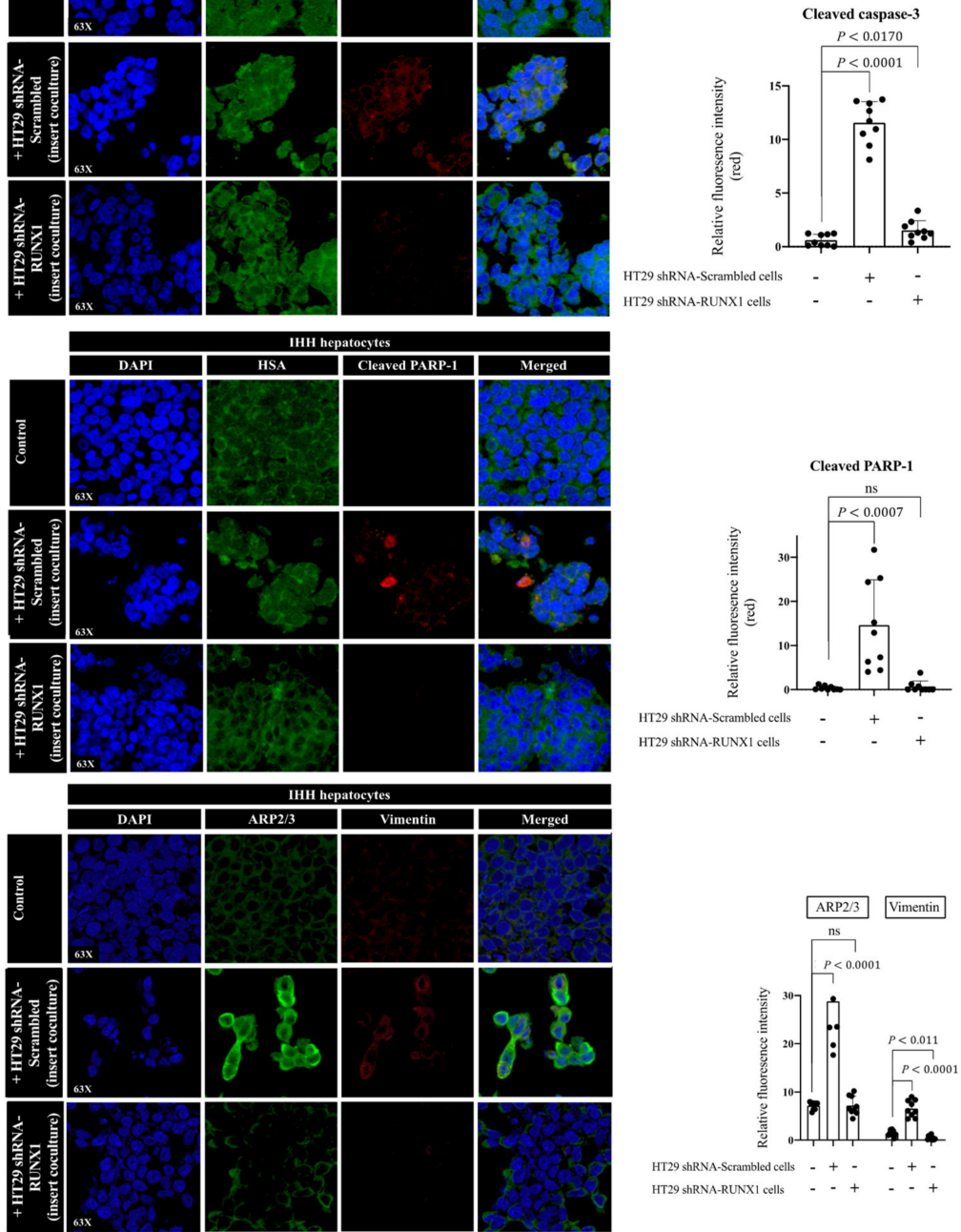

Figure 5. The expression of RUNX1 in cancer cells is crucial for interactions between cancer cells and hepatocytes. (a) represents immunoblotting of RUNX1 in HT29 cancer cells expressing either shRNA-scrambled or shRNA-RUNX1. (b) Cell viability was assessed with MTT assay in IHH cells cocultured with HT29 colorectal cancer cells expressing shRNA-scrambled or shRNA-RUNX1. (c-e) represent co-IF of IHH hepatocytes cocultured with HT29 cancer cells expressing shRNA control or shRNA against RUNX1. The cells were stained with HSA and cleaved caspase-3, HSA and cleaved PARP-1, or ARP2/3 and vimentin, respectively. Average pixel intensity was measured from three randomly selected areas for each sample. The right panels represent the quantification of positive pixels. Results are representative of 3 independent experiments. The bar chart shows mean values \pm SD. $n s=$ Not significant. 
To further ascertain the effect of RUNX1 on hepatocytes alterations, we used the tumour specimens that we previously generated from the intrahepatic xenograft mouse model [32]. These hepatic lesions were generated by injecting HT29 cancer cells expressing scrambled or RUNX1 shRNA into SCID beige mice intrahepatically as explained in Rada et al.'s publication [32]. Of note, our previous publication [32] had reported that the RUNX1-silenced cancer cells were less capable of generating liver metastasis, as well as forming vessel co-opting lesions compared to control cancer cells. To examine whether the absence of RUNX1 in the cancer cells affects cancer cell-driven hepatocyte modifications in vivo, we stained specimens that were generated from our previous publication [32] with PARP-1, ARP2/3, or E-cadherin antibody. Interestingly, we observed a lower expression of cleaved PARP-1 and ARP2/3 in the hepatocytes of metastatic lesions that were generated from RUNX1-deficient HT29 cancer cells in comparison to those that were generated by control HT29 cancer cells (Figure 6a). In contrast, E-cadherin was highly expressed in the hepatocytes of RUNX1-silenced metastatic lesions (Figure 6a).

It is worth mentioning that we previously reported the upregulation of TGF $\beta 1$ in vessel co-opting CRCLM lesions [32]. Accordingly, RUNX1 played a key role in the expression of TGF $\beta 1$ through its target gene thrombospondin 1 (TSP1) in vessel co-opting CRCLM [32]. Importantly, TGF $\beta 1$ was reported as an inducer of apoptosis, EMT, and motility in various cells, including hepatocytes [56]. As shown in Supplementary Figures S4a and S7, the conditioned media of cocultured IHH hepatocytes with cancer (LS174, SW620 or HT29) cells showed a higher abundance of TGF $\beta 1$ compared to the control. Remarkably, our immunoblotting data suggested an overexpression of TGF $\beta 1$ in cocultured IHH hepatocytes (Supplementary Figure S4b) and cancer cells (Supplementary Figure S4c). However, further studies are required to determine the main source of TGF $\beta 1$.

To identify the effect of TGF $\beta 1$ on phenotypic alterations in hepatocytes, we exposed IHH hepatocytes to 100 picomolar recombinant TGF $\beta 1$ for $24 \mathrm{~h}$. We observed the overexpression of cleaved caspase-3, cleaved PARP-1, vimentin, and ARP2/3 in IHH hepatocytes upon exposure to recombinant TGF $\beta 1$ (Supplementary Figure S4d). Overall, our results confirmed the governing role of RUNX1 in cancer cell-driven phenotype modifications in hepatocytes, which facilitated hepatocyte displacement (Figure 6b). However, further investigations are needed to identify other relevant molecules that mediate cancer cell-dependent phenotypic alterations in hepatocytes. 

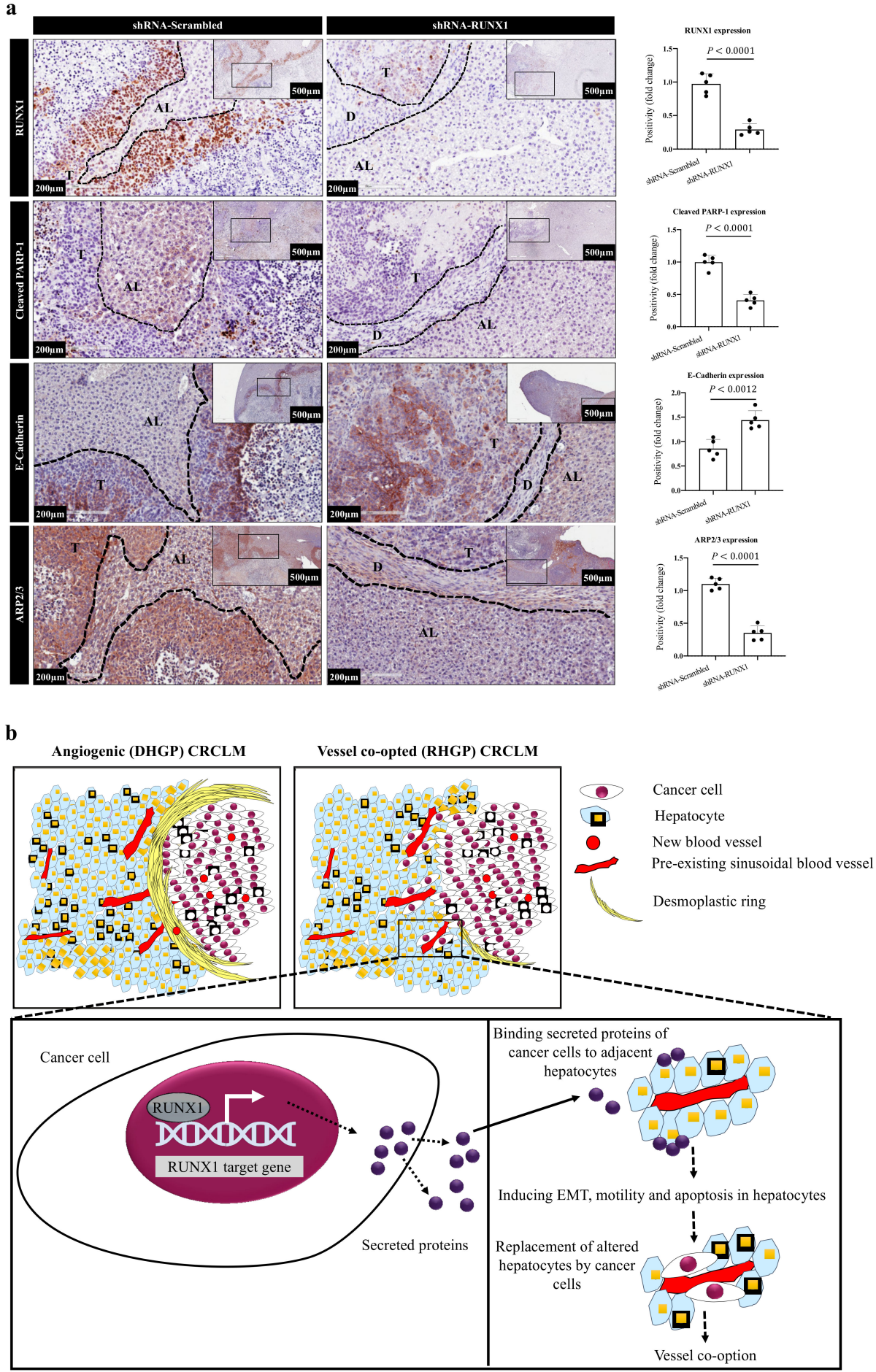

Figure 6. RUNX1 plays a critical role in the interaction between cancer cells and hepatocytes in vivo. (a) represents immunohistochemical staining of liver metastatic tumour sections that were generated using HT29 cancer cells expressing shRNA control or shRNA against RUNX1. AL—adjacent liver; Ddesmoplastic ring; DL—distal liver; T—tumour. The right panels represent quantification of staining positivity that was assessed in the specimens using Aperio software. (b) Schematic illustration showing the main findings in the current study. RUNX1 plays a critical role in the process of hepatocyte displacement by cancer cells. RUNX1 upregulation results in overexpression of its target genes. The expression and secretion of these proteins by cancer cells may stimulate apoptosis, EMT and/or motility of hepatocytes in the surrounding liver. Through these processes, cancer cells induce hepatocyte displacement and replacement around the pre-existing blood vessels and occupy their space to form vessel co-option. 


\section{Discussion}

We previously hypothesized that vessel co-option occurs in four different fluid phases in CRCLM: (a.) increase in the motility of cancer cells to infiltrate surrounding parenchyma; (b.) displacement of the hepatocytes at the edge of tumour nests and occupation of their space by cancer cells; (c.) physical contact between cancer cells and sinusoidal vessels; (d.) forming immune microenvironment that favours vessel co-option [13]. Our team reported the molecular signaling of cancer cell motility in vessel co-opting lesions, which are mainly associated with RUNX1 [32] and ARP2/3 [8,32] overexpression. However, the pathways underlying hepatocyte displacement were not investigated yet. Herein, our extensive studies including in vitro and in vivo analyses uncovered the molecular pathways that contribute to hepatocyte displacement, which involves apoptosis, EMT, and motility. However, the question of whether these processes proceed concurrently or consecutively requires additional investigation.

Various studies have investigated the role of apoptosis in nonangiogenic and antiangiogenic resistant tumours $[22,23,57,58]$. These studies have mainly focused on the role of apoptosis in cancer cells instead of their microenvironment. In this context, it has been reported that proapoptotic genes, including FOS, FAH, and $\mathrm{PRODH}$, are upregulated in the cancer cells of nonangiogenic NSCLC [22]. On the other hand, high levels of serpin B2 (SERPINB2) have been demonstrated in the cancer cells of vessel co-opting brain metastatic lesions, which play a key role in apoptosis suppression $[57,58]$. These findings were consistent with our results, which suggested low expression levels of proapoptotic biomarkers (cleaved caspase-3 and cleaved PRAP-1) in the cancer cells of CRCLM lesions.

EMT is a pivotal process that is implicated in invasiveness and metastatic behaviour of epithelial cancers, and it also correlates with poor clinical outcomes in several solid tumours [59]. EMT has been shown to increase cancer cell motility that favours invasion and dissemination $[30,60]$. It has been suggested that partial EMT is associated with tumour resistance to chemotherapy [61] and antiangiogenic treatments [62,63]. Of note, vessel coopting tumours are also known to be resistant to antiangiogenic therapy [8]. We recently demonstrated that both EMT and motility are essential for cancer cell infiltration within liver parenchyma in CRCLM [32]. In the current study, we also found a positive correlation between EMT and motility in hepatocytes and vessel co-option.

The cancer cells of vessel co-opting CRCLM lesions were characterized by a high expression of RUNX1 that correlated with the upregulation of its target genes, including TSP1 [32]. Accordingly, the secreted TSP1 by cancer cells augmented the expression and activation of TGF $\beta 1$ in the hepatocytes in their neighbouring hepatocytes [32]. In this study, our data proposed RUNX1 and TGF $\beta 1$ as key mediators of hepatocyte displacement. In agreement with our data, TGF $\beta 1$ has been shown to induce apoptosis $[64]$ and EMT $[65,66]$. Despite the lack of literature that suggests a positive correlation between TGF $\beta 1$ and hepatocyte motility, our in vitro data confirmed that exposing hepatocytes to TGF $\beta 1$ leads to the upregulation of the motility marker (ARP2/3) in hepatocytes.

Our study suggests that cancer cells stimulate apoptosis and EMT in hepatocytes through the overexpression of TGF $\beta 1$. Then, a question arises as to whether these two processes occurred simultaneously or sequentially? In agreement with our study, it has been reported that TGF $\beta 1$ can stimulate apoptotic and EMT responses in AML-12 mouse hepatocytes in a dose- and time-dependent manner [67]. Accordingly, the net effect of TGF $\beta 1$ was contingent on the cellular context and the specific state of cells, such as the genetic basis and cell cycle state. Therefore, further investigation needs to determine the reasons underlying the differential response of hepatocytes to cancer cells in vessel co-opting CRCLM lesions.

In conclusion, our data uncovered RUNX1 and TGF $\beta 1$ signaling pathways as major pathways that orchestrate hepatocyte displacement in CRCLM to form vessel co-option, which was arbitrated by apoptosis, EMT, and motility. The presented mechanisms provide further insights into the processes involved in vessel co-option in CRCLM. However, more investigations are needed to address all mediators that contribute to hepatocyte displace- 
ment, which would be pivotal in finding new strategies to overcome the development of vessel co-option and resistance to antiangiogenic therapy in CRCLM.

Supplementary Materials: The following supporting information can be downloaded at: https: / / www.mdpi.com/article/10.3390/cancers14051318/s1, Figure S1: Effect of cancer cells on viability in hepatocytes, Figure S2: Expression of autophagy markers in chemonaive CRCLM specimens, Figure S3: The role of RUNX1 in cancer cell-dependent hepatocyte apoptosis, Figure S4: TGF $\beta 1$ mediates cancer cell-driven hepatocytic alterations in vitro, Figure S5: Original uncropped western blots of Figure 2b, Figure S6: Original uncropped western blots of Figure 5a, Figure S7: Original uncropped western blots of Figure S4.

Author Contributions: Conceptualization, M.R., A.L. and P.M.; methodology, M.R., M.T., A.K.-L., J.B., S.P., D.H.K. and N.H.; resources, P.M.; data curation, M.R.; writing-original draft preparation, M.R.; writing - review and editing, M.R., A.L. and P.M. funding acquisition, P.M. All authors have read and agreed to the published version of the manuscript.

Funding: This research received no external funding.

Institutional Review Board Statement: The study was conducted in accordance with the Declaration of Helsinki, and approved by the McGill University Health Centre Institutional Review Board (SDR11-066, 2013).

Informed Consent Statement: Informed consent was obtained from all subjects involved in the study.

Data Availability Statement: The data presented in this study are available within the article.

Acknowledgments: The authors would like to acknowledge the support provided by Dana Massaro and Ken Verdoni (Liver Metastases Research Fellowship). The authors thank RI-MUHC (Liver Disease Biobank) for providing CRCLM slides. The authors also thank all those patients who participated in this study and whose samples were pivotal to this research.

Conflicts of Interest: The authors declare no conflict of interest.

\section{References}

1. Bray, F.; Ferlay, J.; Soerjomataram, I.; Siegel, R.L.; Torre, L.A.; Jemal, A. Global Cancer Statistics 2018: GLOBOCAN Estimates of Incidence and Mortality Worldwide for 36 Cancers in 185 Countries. CA Cancer J. Clin. 2018, 68, 394-424. [CrossRef] [PubMed]

2. Buzzelli, J.N.; Ouaret, D.; Brown, G.; Allen, P.D.; Muschel, R.J. Colorectal cancer liver metastases organoids retain characteristics of original tumour and acquire chemotherapy resistance. Stem Cell Res. 2018, 27, 109-120. [CrossRef] [PubMed]

3. Barugel, M.E.; Vargas, C.; Waltier, G.K. Metastatic colorectal cancer: Recent advances in its clinical management. Expert Rev. Anticancer Ther. 2009, 9, 1829-1847. [CrossRef]

4. Bingham, G.; Shetye, A.; Suresh, R.; Mirnezami, R. Impact of primary tumour location on colorectal liver metastases: A systematic review. World J. Clin. Oncol. 2020, 11, 294-307. [CrossRef]

5. Fusai, G.; Davidson, B.R. Strategies to Increase the Resectability of Liver Metastases from Colorectal Cancer. Dig. Surg. 2003, 20, 481-496. [CrossRef] [PubMed]

6. Zarour, L.R.; Anand, S.; Billingsley, K.G.; Bisson, W.H.; Cercek, A.; Clarke, M.F.; Coussens, L.M.; Gast, C.E.; Geltzeiler, C.B.; Hansen, L.; et al. Colorectal Cancer Liver Metastasis: Evolving Paradigms and future directions. Cell. Mol. Gastroenterol. Hepatol. 2017, 3, 163-173. [CrossRef]

7. Dam, P.V.; Van Der Stok, E.P.; Teuwen, L.A.; Van Den Eynden, G.G.; Illemann, M.; Frentzas, S.; Majeed, A.W.; Eefsen, R.L.; Van den Braak, R.R.J.C.; Lazaris, A.; et al. International consensus guidelines for scoring the histopathological growth patterns of liver metastasis. Br. J. Cancer 2017, 117, 1427-1441.

8. Frentzas, S.; Simoneau, E.; Bridgeman, V.L.; Vermeulen, P.B.; Foo, S.; Kostaras, E.; Nathan, M.; Wotherspoon, A.; Gao, Z.; Shi, Y.; et al. Vessel co-option mediates resistance to anti-angiogenic therapy in liver metastases. Nat. Med. 2016, 22, 1294-1302. [CrossRef]

9. Van den Eynden, G.G.; Bird, N.C.; Majeed, A.W.; Van Laere, S.; Dirix, L.Y.; Vermeulen, P.B. The histological growth pattern of colorectal cancer liver metastases has prognostic value. Clin. Exp. Metastasis 2012, 29, 541-549. [CrossRef]

10. Lazaris, A.; Amri, A.; Petrillo, S.K.; Zoroquiain, P.; Ibrahim, N.; Salman, A.; Gao, Z.; Vermeulen, P.B.; Metrakos, P. Vascularization of colorectal carcinoma liver metastasis: Insight into stratification of patients for anti-angiogenic therapies. J. Pathol. Clin. Res. 2018, 4, 184-192. [CrossRef]

11. Ibrahim, N.; Lazaris, A.; Rada, M.; Petrillo, S.; Huck, L.; Hussain, S.; Ouladan, S.; Gao, Z.; Gregorieff, A.; Essalmani, R.; et al. Angiopoietin1 Deficiency in Hepatocytes Affects the Growth of Colorectal Cancer Liver. Cancers 2020, 12, 35. [CrossRef] [PubMed] 
12. Palmieri, V.; Lazaris, A.; Mayer, T.; Petrillo, S.; Alamri, H.; Rada, M.; Jarrouj, G.; Park, W.; Gao, Z.; McDonald, P.P.; et al. Neutrophils expressing lysyl oxidase-like 4 protein are present in colorectal cancer Therapy, metastases resistant to anti-angiogenic. J. Pathol. 2020, 251, 213-223. [CrossRef] [PubMed]

13. Rada, M.; Lazaris, A.; Kapelanski-Lamoureux, A.; Mayer, T.Z.; Metrakos, P. Tumour microenvironment conditions that favor vessel co-option in colorectal cancer liver metastases: A theoretical model. Semin. Cancer Biol. 2020, 71, 52-64. [CrossRef] [PubMed]

14. Elmore, S. Apoptosis: A Review of Programmed Cell Death. Toxicol. Pathol. 2007, 35, 495-516. [CrossRef] [PubMed]

15. Chaitanya, G.V.; Alexander, J.S.; Babu, P.P. PARP-1 cleavage fragments: Signatures of cell-death proteases in neurodegeneration. Cell Commun. Signal. 2010, 8, 31. [CrossRef] [PubMed]

16. Rada, M.; Vasileva, E.; Lezina, L.; Marouco, D.; Antonov, A.V.; Macip, S.; Melino, A.; Barlev, N.A. Human EHMT2/G9a activates p53 through methylation-independent mechanism. Oncogene 2017, 36, 922-932. [CrossRef]

17. Althubiti, M.; Rada, M.; Samuel, J.; Escorsa, J.M.; Najeeb, H.; Lee, K.G.; Lam, K.; Jones, G.D.D.; Barlev, N.A.; Macip, S. BTK modulates p53 activity to enhance apoptotic and senescent responses. Cancer Res. 2016, 76, 5405-5414. [CrossRef]

18. Nallanthighal, S.; Rada, M.; Heiserman, J.P.; Cha, J.; Sage, J.; Zhou, B.; Yang, W.; HU, Y.; Korgaonkar, C.; Hanos, C.T.; et al. Inhibition of collagen XI alpha 1-induced fatty acid oxidation triggers apoptotic cell death in cisplatin-resistant ovarian cancer. Cell Death Dis. 2020, 11, 258. [CrossRef]

19. Rada, M.; Barlev, N.; Macip, S. BTK modulates p73 activity to induce apoptosis independently of p53. Cell Death Discov. 2018, 4, 95. [CrossRef]

20. Rada, M.; Barlev, N.; Macip, S. BTK: A two-faced effector in cancer and tumour suppression. Cell Death Dis. 2018, 9, 10-12. [CrossRef]

21. Rada, M.; Nallanthighal, S.; Cha, J.; Ryan, K.; Sage, J.; Eldred, C.; Ullo, M.; Orsulic, S.; Cheon, D. Inhibitor of apoptosis proteins (IAPs) mediate collagen type XI alpha 1-driven cisplatin resistance in ovarian cancer. Oncogene 2018, 37, 4809-4820. [CrossRef] [PubMed]

22. Hu, J.; Bianchi, F.; Ferguson, M.; Cesario, A.; Margaritora, S.; Granone, P.; Goldstraw, P.; Tetlow, M.; Ratcliffe, C.; Nicholson, A.G.; et al. Gene expression signature for angiogenic and nonangiogenic non-small-cell lung cancer. Oncogene 2005, 24, 1212-1219. [CrossRef] [PubMed]

23. Coelho, A.L.; Gomes, M.P.; Catarino, R.J.; Rolfo, C.; Lopes, A.M.; Medeiros, R.M.; Araújo, A.M. Angiogenesis in NSCLC: Is vessel co-option the trunk that sustains the branches? Oncotarget 2017, 8, 39795-39804. [CrossRef]

24. Huang, F.; Wang, B.R.; Wang, Y.G. Role of autophagy in tumourigenesis, metastasis, targeted therapy and drug resistance of hepatocellular carcinoma. World J. Gastroenterol. 2018, 24, 4643-4651. [CrossRef] [PubMed]

25. Czaja, M.J.; Ding, W.X.; Donohue, T.M.; Friedman, S.L.; Kim, J.S.; Komatsu, M.; Lemasters, J.J.; Lemoine, A.; Lin, J.D.; Ou, J.J.; et al Functions of autophagy in normal and diseased liver. Autophagy 2013, 9, 1131-1158. [CrossRef] [PubMed]

26. Zhao, Z.; Xia, G.; Li, N.; Su, R.; Chen, X.; Zhong, L. Autophagy inhibition promotes bevacizumab-induced apoptosis and proliferation inhibition in colorectal cancer cells. J. Cancer 2018, 9, 3407-3416. [CrossRef] [PubMed]

27. Chandra, A.; Rick, J.; Yagnik, G.; Aghi, M.K. Autophagy as a mechanism for anti-angiogenic therapy resistance. Semin. Cancer Biol. 2020, 66, 75-88. [CrossRef] [PubMed]

28. Kalluri, R.; Weinberg, R.A. The basics of epithelial-mesenchymal transition. J. Clin. Investig. 2009, 119, 1420-1428. [CrossRef]

29. Roche, J. The epithelial-to-mesenchymal transition in cancer. Cancers 2018, 10, 52. [CrossRef]

30. Son, H.; Moon, A. Epithelial-mesenchymal transition and cell invasion. Toxicol. Res. 2013, 26, 245-252. [CrossRef]

31. Lv, X.Q.; Qiao, X.R.; Su, L.; Chen, S.Z. Honokiol inhibits EMT-mediated motility and migration of human non-small cell lung cancer cells in vitro by targeting c-FLIP. Acta Pharmacol. Sin. 2016, 37, 1574-1586. [CrossRef] [PubMed]

32. Rada, M.; Kapelanski-Lamoureux, A.; Petrillo, S.; Tabariès, S.; Siegel, P.; Reynolds, A.R.; Lazaris, A.; Metrakos, P. Runt related transcription factor-1 plays a central role in vessel co-option of colorectal cancer liver metastases. Commun. Biol. 2021, 4, 950. [CrossRef] [PubMed]

33. Choi, S.S.; Diehl, A.M. Epithelial-to-mesenchymal transitions in the liver. Hepatology 2009, 50, 2007-2013. [CrossRef] [PubMed]

34. Kaimori, A.; Potter, J.; Kaimori, J.Y.; Wang, C.; Mezey, E.; Koteish, A. Transforming growth factor- $\beta 1$ induces an epithelial-tomesenchymal transition state in mouse hepatocytes in vitro. J. Biol. Chem. 2007, 282, 22089-22101. [CrossRef] [PubMed]

35. Lesch, H.P.; Laitinen, A.; Peixoto, C.; Vicente, T.; Makkonen, K.E.; Laitinen, L.; Pikkarainen, J.T.; Samaranayake, H.; Alves, P.M.; Carrondo, M.J.T.; et al. Production and purification of lentiviral vectors generated in 293T suspension cells with baculoviral vectors. Gene Ther. 2011, 18, 531-538. [CrossRef] [PubMed]

36. Rada, M. Characterisation of Novel Post-translational Modulators of p53. Ph.D. Thesis, University of Leicester, Leicester, UK, 2016 Available online: https:/ /leicester.figshare.com/articles/thesis/Characterisation_of_Novel_Post-translational_Modulators_of_ p53/10178642 (accessed on 17 October 2021).

37. Rada, M.; Althubiti, M.; Ekpenyong-Akiba, A.E.; Lee, K.-G.; Lam, K.P.; Fedorova, O.; Barlev, N.A.; Macip, S. BTK blocks the inhibitory effects of MDM2 on p53 activity. Oncotarget 2017, 8, 106639-106647. [CrossRef]

38. Schippers, I.J.; Moshage, H.; Roelofsen, H.; Mu, M.; Ruiters, M.; Kuipers, F. Immortalized human hepatocytes as a tool for the study of hepatocytic. Cell Biol. Toxicol. 1997, 13, 375-386. [CrossRef] [PubMed]

39. Hang, H.; Liu, X.; Wang, H.; Xu, N.; Bian, J.; Zhang, J. Hepatocyte nuclear factor 4A improves hepatic di ff erentiation of immortalized adult human hepatocytes and improves liver function and survival. Exp. Cell Res. 2017, 360, 81-93. [CrossRef] 
40. Farra, R.; Dapas, B.; Pozzato, G.; Scaggiante, B.; Agostini, F.; Zennaro, C.; Grassi, M.; Rosso, N.; Giansante, C.; Fiotti, N.; et al. Effects of E2F1—cyclin E1-E2 circuit down regulation in hepatocellular carcinoma. Dig. Liver Dis. 2011, 43, 1006-1014. [CrossRef]

41. Khezri, R.; Holland, P.; Schoborg, T.A.; Abramovich, I.; Takáts, S.; Dillard, C.; Jain, A.; O’Farrell, F.; Schultz, S.W.; Hagopian, W.M.; et al. Host autophagy mediates organ wasting and nutrient mobilization for tumour growth. EMBO J. 2021, 40, e107336. [CrossRef]

42. Katheder, N.S.; Khezri, R.; O’Farrell, F.; Schultz, S.W.; Jain, A.; Rahman, M.M.; Schink, K.O.; Theodossiou, T.A.; Johansen, T.; Juhász, G.; et al. Microenvironmental autophagy promotes tumour growth. Nature 2017, 541, 417-420. [CrossRef] [PubMed]

43. Pankiv, S.; Clausen, T.H.; Lamark, T.; Brech, A.; Bruun, J.A.; Outzen, H.; Øvervatn, A.; Bjørkøy, G.; Johansen, T. p62/SQSTM1 binds directly to Atg8/LC3 to facilitate degradation of ubiquitinated protein aggregates by autophagy. J. Biol. Chem. 2007, 282, 24131-24145. [CrossRef]

44. Runwal, G.; Stamatakou, E.; Siddiqi, F.H.; Puri, C.; Zhu, Y.; Rubinsztein, D.C. LC3-positive structures are prominent in autophagydeficient cells. Sci. Rep. 2019, 9, 10147. [CrossRef] [PubMed]

45. Niklaus, M.; Adams, O.; Berezowska, S.; Zlobec, I.; Graber, F.; Slotta-Huspenina, J.; Nitsche, U.; Rosenberg, R.; Tschan, M.P.; Langer, R. Expression analysis of LC3B and p62 indicates intact activated autophagy is associated with an unfavorable prognosis in colon cancer. Oncotarget 2017, 8, 54604-54615. [CrossRef] [PubMed]

46. Kim, J.S.; Bae, G.E.; Kim, K.H.; Lee, S.-I.; Chung, C.; Lee, D.; Lee, T.H.; Kwon, I.S.; Yeo, M. Prognostic significance of LC3B and p62/SQSTM1 expression in gastric adenocarcinoma. Anticancer Res. 2019, 39, 6711-6722. [CrossRef]

47. Wu, S.; Du, Y.; Beckford, J.; Alachkar, H. Upregulation of the EMT marker vimentin is associated with poor clinical outcome in acute myeloid leukemia. J. Transl. Med. 2018, 16, 170. [CrossRef]

48. Molinie, N.; Gautreau, X.A. The Arp2/3 Regulatory System and Its Deregulation in Cancer. Physiol. Rev. 2018, 98, 215-238. [CrossRef]

49. Mendonsa, A.M.; Na, T.Y.; Gumbiner, B.M. E-cadherin in contact inhibition and cancer. Oncogene 2018, 37, 4769-4780. [CrossRef]

50. Browne, G.; Taipaleenmäki, H.; Bishop, N.M.; Madasu, S.C.; Shaw, L.M.; Van Wijnen, A.J.; Stein, J.L.; Stein, G.S.; Lian, J.B. Runx1 is associated with breast cancer progression in MMTV- PyMT transgenic mice and its depletion in vitro inhibits migration and invasion. J. Cell Physiol. 2015, 230, 2522-2532. [CrossRef]

51. Iwatsuki, K.; Tanaka, K.; Kaneko, T.; Kazama, R.; Okamoto, S.; Nakayama, Y.; Ito, Y.; Satake, M.; Takahashi, S.; Miyajima, A.; et al. Runx1 promotes angiogenesis by downregulation of insulin-like growth factor-binding protein-3. Oncogene 2005, 24, 1129-1137. [CrossRef]

52. Sangpairoj, K.; Vivithanaporn, P.; Apisawetakan, S.; Chongthammakun, S.; Sobhon, P.; Chaithirayanon, K. RUNX1 Regulates Migration, Invasion, and Angiogenesis via p38 MAPK Pathway in Human Glioblastoma. Cell. Mol. Neurobiol. 2017, 37, 1243-1255. [CrossRef] [PubMed]

53. Chen, Y.; Zhang, L.; Liu, L.; Sun, S.; Zhao, X.; Wang, Y.; Zhang, Y.; Du, J.; Gu, L. Rasip1 is a RUNX1 target gene and promotes migration of NSCLC cells. Cancer Manag. Res. 2018, 10, 4537-4552. [CrossRef] [PubMed]

54. Ter Elst, A.; Ma, B.; Scherpen, F.J.G.; De Jonge, H.J.M.; Douwes, J.; Wierenga, A.T.J.; Kamps, W.A.; de Bont, E.S.J.M. Repression of vascular endothelial growth factor expression by the runt-related transcription factor 1 in acute myeloid leukemia. Cancer Res. 2011, 71, 2761-2771. [CrossRef]

55. Dowdy, C.R.; Xie, R.; Frederick, D.; Hussain, S.; Zaidi, S.K.; Vradii, D.; Javad, A.; Li, X.; Jones, S.N.; Lian, J.B.; et al. Definitive hematopoiesis requires Runx1 C-terminal-mediated subnuclear targeting and transactivation. Hum. Mol. Genet. 2010, 19, 1048-1057. [CrossRef] [PubMed]

56. Xu, J.; Lamouille, S.; Derynck, R. TGF-B-induced epithelial to mesenchymal transition. Cell Res. 2009, 19, 156-172. [CrossRef] [PubMed]

57. Valiente, M.; Obenauf, A.C.; Jin, X.; Chen, Q.; Zhang, X.H.; Lee, D.J.; Chaft, J.E.; Kris, M.G.; Huse, J.T.; Brogi, E.; et al. Serpins Promote Cancer Cell Survival and Vascular Co-Option in Brain Metastasis. Cell 2014, 156, 1002-1016. [CrossRef]

58. Donnem, T.; Reynolds, A.R.; Kuczynski, E.A.; Gatter, K.; Vermeulen, P.B.; Kerbel, R.S.; Harris, A.L.; Pezzella, F. Non-angiogenic tumours and their influence on cancer biology. Nat. Rev. Cancer 2018, 18, 323-336. [CrossRef] [PubMed]

59. Montemagno, C.; Pagès, G. Resistance to Anti-angiogenic Therapies: A Mechanism Depending on the Time of Exposure to the Drugs. Front. Cell Dev. Biol. 2020, 8, 584. [CrossRef]

60. Brabletz, T.; Kalluri, R.; Nieto, M.A.; Weinberg, R.A. EMT in cancer. Nat. Rev. Cancer 2018, 18, 128-134. [CrossRef]

61. Elaskalani, O.; Razak, N.B.A.; Falasca, M.; Metharom, P. Epithelial-mesenchymal transition as a therapeutic target for overcoming chemoresistance in pancreatic cancer. World J. Gastrointest. Oncol. 2017, 9, 37-41. [CrossRef]

62. Cooke, V.G.; LeBleu, V.S.; Keskin, D.; Khan, Z.; O'Connell, J.T.; Teng, Y.; Duncan, M.B.; Xie, L.; Maeda, G.; Von, S.; et al. Pericyte depletion results in hypoxia-associated epithelial-to-mesenchymal transition and metastasis mediated by met signaling pathway. Cancer Cell 2012, 21, 66-81. [CrossRef] [PubMed]

63. Maione, F.; Capano, S.; Regano, D.; Zentilin, L.; Giacca, M.; Casanovas, O.; Bussolino, F.; Serini, G.; Giraudo, E. Semaphorin. 3A overcomes cancer hypoxia and metastatic dissemination induced by antiangiogenic treatment in mice. J. Clin. Investig. 2012, 122, 1837-1848. [CrossRef] [PubMed]

64. Black, D.; Lyman, S.; Qian, T.; Lemasters, J.J.; Rippe, R.A.; Nitta, T.; Kim, J.; Behrn, K.E. Transforming growth factor beta mediates hepatocyte apoptosis through Smad3 generation of reactive oxygen species. Biochimie 2007, 89, 1464-1473. [CrossRef] [PubMed] 
65. Kim, K.K.; Sheppard, D.; Chapman, H.A. TGF- $\beta 1$ signaling and tissue fibrosis. Cold Spring Harb. Perspect. Biol. 2018,10 , a022293. [CrossRef] [PubMed]

66. Fabregat, I.; Caballero-Díaz, D. Transforming growth factor- $\beta$-induced cell plasticity in liver fibrosis and hepatocarcinogenesis. Front. Oncol. 2018, 8, 357. [CrossRef]

67. Song, J. EMT or apoptosis: A decision for TGF- $\beta$. Cell Res. 2007, 17, 289-290. [CrossRef] 